\title{
RESEARCH NOTE: IMPERSONAL DECISION-MAKING AS A FRAUDULENT IDEOLOGY
}

\section{Peter A. Remender \\ University of WisconsinOshkosh}

Mid-American Review of Sociology, 1993, Vol XVII, No. 2: 39-50

Presented at "The Paradoxes of Modernity: Structure, Rationalin and Decision" session of the Midwest Sociological Society meeting. Des Moines, Iowa. April, 199I.

\section{INTRODUCTION}

As a young sociologist, I had come to believe that formal organizations were for the most part bureaucratic structures and that "Bureaucratization offers above all the optimum possibility for carrying through the principle of specializing administrative functions according to purely objective considerations." (Gerth and Mills 1946:215). My expectations were that people evaluating others would look objectively at the evidence and render an equitable decision. that is, that they would actually be impersonal decision-makers. Over the years I have found this not always to be the case. Since sociologists are dealing with probability statements, it is possible to conclude that one has become overly attentive to the exceptions to the rule. Perhaps, one has taken note of a "private trouble" and there is no basis to make a "public issuc" out of a few cases (sce Mills, 1962:295-402). Since this writer has had over iwenty years of experience as a faculty member at a mid-western university. it is possible to examine the "issue" empirically by reference to individual cases. Having embarked upon that task, some effort was made to cross check the lindings against cases outside the university experience.

\section{METHODS}

It is difficult if not impossible to gather systematic data about decisionmaking at the university level given the confidential nature of the process. One of my former colleagues found that he could not systematically compare his credentials with those of successful candidates for tenure because the administration would not release the data (Remender, 1991:19). Belatedly he was able to obtain comparative data on professional achievements - publications, paper presentations - but no comparative data on teaching or service. My work suffers from a similar difficulty. This study is not a systematic or representative consideration of all possible cases over a particular period of time but a focus on selected cases for which this investigator was able to obtain detailed documentation. The cases that are dealt with are those where decision-makers appear to have acted with prejudice based upon inappropriate considerations. 
This is a selective look at cases of personnel decisions in which there appears to be a less than impersonal evaluation of the available evidence. The data has been collected over a period of several years and is restricted to personnel decisions (renewal-tenure-promotions) at the university level. Conclusions are based upon the study of one midwestern university.

This paper may be viewed as an attempt at the discovery of grounded theory through direct observations. "...grounded theory is derived from data and then throusteristic examples of data." (Glaser and Strauss 1967:5). The illustrated by a conflict model of decision-making as an intent of the author is to propose a conflict model of decision-making as an alternative to the notion of impersonal decision making. The reader is invited to resolve in their mind the relative merit of the two models. The style of scholarship in this paper is intended to be critically analytical. My argument is that one can derive guidelines for the "malevolent" from the actual cases considered. The reader should decide which of the two models least violates empirical reality.

\section{THE "CONSERVATIVE" MODEL}

Sociology has had its full measure of conservative idcology including the Surwism of William Graham Sumner and the Davis-Moore hypothesis Social Darwinism of William Graham Sumner and the Davis-Moore point draws us a picture of a meritocracy or a system based upon individual merit. For classical picturomists, it is the impersonal forces of the marketplace (also known as the Law of Supply and Demand) which creates this desired structure of social inequality with the "Superior" people receiving their just rewards as an appropriate incentive to encourage them to make their contribution to society. Sumner $(1963$ :157) viewed millionaires as a product of natural selection. Superior people apparently not only survive - they thrive. We are asked to believe that it is a case of contest mobility with sponsored mobility (see Turner 1960) being ignored by the proponents of elitist hegemony.

Contemporary sociologists might find the notion of an "invisible hand" too ieificd a view of society and of social forces. Suppose, we rationalize the system and recognize human agency tut make the agent an-imperscnal tesreaucrat. This element Max Weber adds to the ultra-conservative view of social inequality. The personnel analyst is said to judge credentials, objectively selecting the best people for available positions. What could be more just than bureaucrats acting in a spirit of detached impersonality?

\section{THE CONFLICT PERSPECTIVE}

This author suggests that we have been deceived by Potemkin villages and that we should recognize the notion of impersonal decision-making as a fraudulent ideology - as a case of the Emperor's clothes! While this conflict model is presented in the form of rules for miscreants, it is not intended to serve the prince in a Machiavellian manner. The author presumes that decision-makers are aware of these rules and that by systematically spelling them out one raises the consciousness of the victims and perhaps of the naive spectators who might not otherwise comprehend the reality of the situation.

1. Make the decision and then search for reasons to justify the action.

One should add "if necessary" since decision-makers are often not held accountable for their actions. Sometimes there is no requirement that "reasons for action" must be provided to the candidate for renewal or promotion. Ignorance is not necessarily blissful.

In cases where it is required that "reasons for action" be provided, there is often no standard of quality to measure the adequacy of these reasons. In conversations with faculty advocates and attorneys who have worked for faculty unions, it has become clear that stated reasons for action may be pretexts for the real reasons which involve consideration of inappropriate factors such as onc's politics.

It is clear to me that there need be no valid relationship between the credentials considered and the conclusions drawn. What protections does one have against decisions which are arbitrary and capricious or motivated by some hidden agenda? The stated (official) reasons may be so overboard as to be meaningless.

Reasons could be helpful in the mentoring process giving guidance to the individual who has been denied promotion or to the individual who has been renewed but is not a strong candidate for tenure without improvement in areas of current deficiency. If one were given the benefit of good advice from administrators or senior faculty, one might be able to adjust one's behavior taking corrective measures to improve performance. It is possible that the process could operate in this manner.

It seems clear to me that some individuals look for reasons to justify their decision - reasoned evaluation is not the basis for the decision. If we look at the situation from the standpoint of the victim, it may be that the individual is very perceptive in finding that the decision-makers explanation doesn't make any sense.

Conservatives would have us believe-that organizational agents * impersonally sift and winnow through documents searching for the truth. objectively evaluating relative worth, ultimately recognizing and rewarding individuals on the basis of merit. Merit is perceived to be a consequence of this careful, deliberative process in which one weighs all the evidence. In contrast. this author proposes that decision-makers often prefer not to be confused by the facts - they know who they like for whatever their reasons. Reasons become after the fact appendages often not subject to scrutiny in depth. If this analysis is correct, we would expect to find a gap between the conclusions drawn and the actual documentary evidence.

In one case, an academic dean argued that the tenure candidate's allegedly weak scholarly record made him no better than an average teacher despite overwhelming direct evidence of teaching effectiveness. Seven of eight members 
of the College of Letters and Science Review Committee gave this candidate the highest possible rating (superior) in the area of teaching ability while the eighth member of the committee rated this individual's teaching as above average. My argument is that the Dean had likely decided against tenure for this candidate and argument is that the Dean hastify his actions. My own interpretation of the same data does not come close to coinciding with the Dean's. I have argued that teaching effectiveness is best measured directly - doing original research is not a prerequisite to being an effective teacher. "Scholars can read the work of others, think about what they have read, and talk and share ideas. Reading and thinking can keep one current or even at the cutting edge." (Remender 1990:41)

In the case cited above, the candidate was unanimously recommended for tenure by the eight member college committee which cited his "unquestionably superior record in the areas of teaching and service." To assert that reasonable superior recon disagree in their "independent" evaluation of the same data, should not lead one to conclude that differences of "opinion" are to be explained as the (c) legitimate consequence of the independent judgment of impersonal decisionmakers. Indeed, a five-member faculty hearing subcommittee found that adversarial rather than collegial behavior on the part of the Dean and the Chancellor colored this tenure decision. The faculty subcommittee further found that the Dean had made four arbitrary assumptions of fact with material prejudice to the faculty member.

It is noteworthy that this individual was denied tenure despite the above findings. A year after this report was filed, the candidate for tenure is no longer at the university while the Dean continued to hold office. Administrative distortion of the facts and prejudicial behavior worked to achieve the outcome the Dean sought - tenure denial. The stated reasons for action need not be predicated upon an impersonal consideration of the evidence. It is clear that there was no accountability in the case cited. The flawed basis for the Dean's action was irrelevant to the outcome of the case. The dislikes of the Dean proved to be the most important variable; the actual merit of the candidate was irrelevant.

The stated reasons did not need to be adequate or valid.

\section{Be selective in your reference to the candidate's credentials.}

The naive student of Max Weber might assume that one actually, reads the available evidence and carefully arrives at an assessment of the strengths and weaknesses of the candidate in each of the criterion areas which are teaching, research, and service (according to the University of Wisconsin system's administrative code which governs the process at my university). One might administrative code which governs the process at me to terms with the evidence. While we might all agree that all perception is selective, the notion of "selective While we might all agree that all perception is selective, the notion of "selective by some faculty and administration. Areas of weakness can be ignored in the case of favored faculty and emphasized in the case of faculty who are disfavored. Points of vulnerability can receive critical attention if one is looking for a reason to be negative. It seems to me that most of us have an Achilles' heel that can be found by those who look hard enough for a reason for what they have decided to do. Conversely, areas of strength need not be mentioned if one has decided to go against a particular candidate.

In one case, the summary statement indicated that the faculty member's student evaluation scores ranged from above average to below average which was correct though hardly reflective of the fact that two-thirds of the candidate's scores were above average. In another case, an administrator chose to make no mention of teaching effectiveness in his evaluative comments though this individual had scores that were routinely in the 80th and even 90 th percentile. One candidate's record in the area of professional and scholarly growth was de-valued on the basis of his publication record while no mention was made of any of the other dimensions of this criterion area that are supposed to be taken into account in the evaluation of his performance. The fact is that the individual had an impressive record of professional development if one took into account papers presented at meetings and other activities that are supposed to count as evidence of scholarly achievement.

It was difficult to know whether peer evaluations of teaching effectiveness had any weight in the evaluative process since narrative comments by evaluators appeared to have focused almost exclusively on student evaluation scores. The support of one's colleagues may be less important than one's popularity with students. If one measure of teaching effectiveness is given importance while another measure is ignored, one might question whether evaluators are adequately assessing the candidate's performance as a teacher.

The point is that there is considerable potential for abuse if one can build one's case for or against a candidate by selectively ignoring or being attentive to particular details. While some degree of discretionary behavior is arguably inevitable, one might expect that an impersonal judge would systematically consider all of the available evidence.

3. Keep the candidate ignorant of the normative expectations (standards).

In response to a request for clarification of the College Promotion Committee's reasons for action, the chair of the committee responded to the candidate denied promotion: "Most of the members of the committee have served before and have concept of what the criteria for promotion to full professor are, the expected level of performance in the three areas of evaluation." The letter did not indicate what the "expected" level of achievement was or where the candidate might find reference to normative standards employed by committee members who allegedly have a concept of what the criteria for promotion are.

If one is expected to meet reasonable normative standards, should one be told what those standards are? Is this a case of playing "I've got a Secret" with faculty careers? Keeping the candidate ignorant strengthens the power of others over the candidate as one can always be found guilty of not having achieved some nebulous standard held in the mind of the decision-makers. This author argues that the maintenance of a closed awareness context is an abuse of power in the case cited above (See Glaser and Strauss, 1964). We are not always dealing with cooperative forms of human interaction and should not assume that the decision-maker's interests are best served by communicating precise standards 
to candidates as the lack of clear standards provides decision-makers with an increased immunity from accountability for their actions.

If one assumes that the "system" is fair, one might council the individual to adjust to the "objective" reality of the situation. Some seem to take the position that the individual should change when the individual fails to measure up to career expectations. "The individual who has embarked on an occupational career with certain mobility aspirations and who has built a self-conception around them, must now remake the self in accord with new realities." (Hewitt 1991:248). What if there are no standards? What if we are blaming the victim?

One faculty hearing subcommittee, which heard the appeal of a non-renewed faculty member, concluded that the department lacked a common set of evaluative criteria and that individual department members did not apply specific evaluative criteria in judging the quality of the candidate's work. If we do not know what the standards are, how does one evaluate the claim that standards do not exist or the claim that they were not actually used by individual decisionmakers? Is there a system of rules which is shared with all parties? Perhaps, ignorance is strength but for whom?

\section{Rules are made to be broken.}

At the university studied, the Faculty Handbook states that professional and scholarly growth "...must be assessed relative to the particular field." The handbook further acknowledges that "Acceptance for publication is easier in some fields than in others." Yet when the chair of the University Promotions Committee was interviewed, he said that the University Promotions Committee would juxtapose the credentials of various candidates from various departments and colleges to see how they would compare with one another. He told me that he would like to see candidates average one publication per year which is a publication rate which exceeded the average for the most prolific sociology department in the country at that time. When other members of the All University Promotions Committee were informed about the relative difficulty of publishing in sociology, it did not appear to have any effect on their thinking. It seems to this writer that the committee failed to take into account disciplinary norms despite a written mandate to do so.

There appears to have been no adherence to the rule that professional achievements be evaluated relative to the particular field. This author argues that quantity should be judged relative to disciplinary norms and that individual faculty performance should be measured against standards derived from peer institutions. The American Sociological Association has made an effort to be responsive to this concern with the publication of Guidelines and Resources for Assessing Your Sociology Program (see Charles S. Green, III, pp. 26-30).

The written rules state that "professional and scholarly growth is most appropriately evaluated at the initial level of review." The College Committee is instructed not to preempt the academic judgements of the initial level of review and the University Committee operates with rules which state that the committee should not attempt to substitute its judgement for lower levels of review. If the committee is to evaluate procedure and to ascertain that criteria have been met as claimed, it would appear that its role is severely circumscribed. In actual practice, committee members seem to see their role as one of rendering "independent judgements" which substitute for those made at the departmental level. The chair of the University Promotions Committee advised one candidate to obtain outside evaluations of his professional achievements apparently on the assumption that the department's review of the candidate carried little weight with committee members. In place of the written rule which gives greatest weight to the department's evaluation of professional achievements, we have substituted an unwritten rule which assigns greater weight to outside evaluators. This is not to dispute the validity of obtaining outside evaluators but to take note of the violation of the written rules and the existence of unwritten rules which were communicated through informal channels.

One faculty member with "favored status" received a promotion despite not providing the minimum evidence of teaching effectiveness required for promotion in rank. Most candidates are expected to provide evidence in excess of the minimum required but less than the minimum number of student evaluations of instruction was deemed acceptable in the case of this faculty member. It would appear that "minimum" does not mean "minimum" when special consideration is to be granted to a particular candidate.

5. If the old rules don't work, make up new ones.

In the Faculty Handbook, we note that "Levels of review shall not use criteria which are not specified by the promotions document or other university regulations." Several violations of this principle were found upon review of available documents. In one case the College Promotions Committee "wondered" (in writing) about the length of a particular article as well as of other articles listed as having been published despite the fact that article length is not a stated basis for evaluating faculty performance. It is especially curious why the committee never asked to see the documentation which would have satisfied any questions committee members had about the length of particular articles. Could it be that the cited reasons for action were a pre-text for a hidden political agenda? Presumably, the length of one's articles had become a basis for rejecting a candidate with an otherwise adequate record of professional achievement. The question about article length was the only cited reason for the committee finding the candidate weak in the area of scholarly and professional growth. Should one conclude that substance is irrelevant since the only narrative reference was to quantity?

One of the faculty interviewed stated that co-authored publications should count less than sole authored publications which is not an unreasonable standard if explicitly articulated as a matter of policy. Since no documents formalize this principle, it would seem that it would be inappropriate to de-value co-authored publications. Yet the reasons for action provided by an all university promotions committee state: "It is recommended that independent, researchbased productivity would strengthen the candidate's evidence to support his promotion." In consultation with a senior colleague, we interpreted "independent" to mean "sole authored." Much could be said for and against sole 
authorship relative to joint activity. This is an issue which merits discussion and a resolution that is made public so all can be aware of the rules by which one is to be judged. My colleague and I were not sure what the committee meant by "research-based productivity" but we presumed that some kinds of scholarly endeavor must count more than other kinds of scholarly activity. Perhaps, the committee was thinking about empirical research vs. theoretical analysis. The formal rules do not differentiate between research-based productivity and other kinds of professional and scholarly growth. Thus, there is considerable ambiguity as to what committee members may have had in their mind when they used the above language to advise the candidate (or perhaps to deny the candidate).

A recent candidate for tenure appears to have been the victim of a "publish or perish" standard unilaterally imposed upon him by his dean. This would seem to be a clear violation of the state administrative code since written criteria are to to be a clear violation of the appropriate institutional faculty bodies. The Faculty Handbook states that "the relative importance of each function of the evaluation process shall be decided by department/equivalent and college faculties in consultation with the appropriate committee of the Faculty Senate..." The Dean appears to have exceeded his authority in establishing a "disqualifying" requirement which does not exist in any of the formal rules of the institution. The candidate provided ample evidence of professional and scholarly growth as required by the formal rules of the institution (but did not meet the Dean's "requirement" for tenure).

6. If there is too much supporting evidence, disqualify the evidence.

The Faculty Handbook states that "Extra-institutional service is that service rendered the broader community which is related to the special academic or professional competencies of a faculty member." This definition would appear to enable decision-makers to distinguish between relevant and irrelevant service. Thus, one candidate was found to be quite active in the community in ways that were discounted by the All University Promotions Committee despite the fact were discounted by the All colleagues found the same service to be relevant to his academic and professional competencies as a sociologist. The case has been argued that community service is applied sociology for-sociologists. (Remender, 1986).

One sociologist managed to offend the Dean by running for Congress against a representative of the dominant Plutocratic (Republican) party. While department faculty viewed his campaign as an expression of his sociological interests and as related to the courses he taught, the Dean labeled it as a job search which took away from his professional obligations. The Dean's denial of tenure for this sociologist would appear to have had a chilling effect on others who might otherwise practice what they talk about in the classroom. What some of us would see as relevant service if not meaningful professional development, others discounted or looked at in negative terms. The same individual does not appear to have had his professional activity counted by the administration as they ignored his papers presented at meetings in evaluating his scholarly activity.
Another faculty member claimed that he receives no credit for consulting with labor union organizations though business faculty are rewarded for consulting with business. Could it be that there is a political basis for deciding what counts and what does not?

\section{Misinterpret the data presented.}

Student evaluation of teaching data must be included by candidates for retention and for promotion as evidence of teaching effectiveness. The university studied has a Standard Evaluation of Teaching Instrument which has a scale ranging from one (low), to five (high). Three is defined as average according to the scale which labels three average. However, three is not average if one is compared in relation to other faculty instead of in relation to the mid-point which the scale says is average.

Suppose sociology faculty average 3.69 using this instrument. Would a faculty member with a 3.46 score be above average because the scale point for average is 3.0, or below average because the departmental norm is 3.69 ? How are we to best interpret student perceptions of teaching effectiveness?

Does an above average teacher (in relation to the mid-point of the scale) become a below average teacher (in relation to others in the department) if department members achieve a high standard of classroom performance? Should the good quality of one's teaching be discredited in comparison to the higher quality instruction offered by one's colleagues? Conversely, might a lousy teacher be regarded as above average because her colleagues are even worse in the classroom? Below average might not be bad in relation to outstanding colleagues.

Need we talk about the social construction of "reality" or of the need to avoid a reified view of our world? Must we all be above average? If so, in relation to what or to whom? On the basis of such non-sense, careers are made or ruined. Do we condemn our colleagues and ourselves to a Sisyphean task?

8. Change the priorities.

The university's promotion policy states explicitly that "consistent with the mission of this university, the most important criterion is teaching effectiveness which is a necessary, but not sufficient, basis for promotion." The policy further states that: "Professional and scholarly. growth is to be given equal, weight with institutional and extra-institutional service." While the renewal/nonrenewal guidelines are silent on the issue of relative weights. one might reasonably expect the same principle would apply since the emphasis on teaching is claimed to be "consistent with the mission of this university" and surely one would not assign relative weights that would be inconsistent with the university's mission. Since the Faculty Handbook states that "The relative importance of each function of the evaluation process shall be decided by department/equivalent and college faculties in consultation with the appropriate committee of the Faculty Senate in accordance with the mission and needs of the university...and its component parts," and that "a written statement of the department/equivalent unit and college criteria shall be made available to all faculty.", it would seem reasonable that the promotion policy must apply to 
renewal/non-renewal since it is the only document which spells out the relative importance of each function and it claims to be consistent with the university's mission which is required of the renewal/non-renewal policy.

One critic claims that "...the academic culture is not merely indifferent to teaching, it is actively hostile to it." (Sykes 1988:54). On this campus, the administration denied tenure to a sociologist who was the recipient of the teaching award given jointly by the State Sociological Association and the American Sociological Association. The Dean's priorities ostensibly favor grantsmanship and publication. Two deans brought in as external consultants charged that this faculty member's department was out of step with the college's current direction which emphasized increased scholarly activity and from the department's point of view, a consequent de-emphasis on teaching. It would appear the Dean had convinced the consultants as to the college's current direction since there was no official college policy at the time and a policy endorsed by the Dean was subsequently defeated in a vote of the college faculty - a vote that occurred after the individual had been denied tenure and his department had been severely criticized for its emphasis on teaching. The Dean clearly connected these two actions in his reasons for action: "The Department of Sociology has been categorized by external consultants as one in which an attitude of anti-intellectualism has metamorphosed the support of teaching into a case against scholarly work in the discipline' which 'threatens the promotion of professional sociology." It is not important in this paper to refute the unsubstantiated allegation of the consultants readily embraced by the Dean of the College. The point is that the priorities were changed unilaterally by the Dean without any formal process as required by the state administrative code and by the Faculty Handbook. "The guiding principle of ruling elites was - and still is: When change threatens to rule, then the rules are changed." (Parenti 1988:182)

\section{CONCLUDING REMARKS}

This paper represents a challenge to the conservative view that ours is a meritocratic system in which universities and other organizations follow formal, written rules, conducting affairs in a spirit of detached impersonality (Abrahamson 1990:105). Those who do not challenge orthodoxy may not experience repression or censorship. "Journalists (like social scientists and others) rarely doubt their own objectivity even as they faithfully echo the established political vocabularies and the prevailing politico-economic orthodoxy. Since they do not cross any forbidden lines, they are not reined in." (Parenti 1986:35). Thus it is with the myth of the meritocracy and its corollary principle of impersonal decision-making. In the case of the individual who received favored treatment in violation of the formal rules, the "sponsored" individual has consistently acted as an agent of the local ruling elite. In each instance of particularistic treatment of a negative nature, the individual had managed to offend the power structure of the university. The evidence cited suggests a politicized process of rewarding friends and punishing perceived
enemies.

Where a system of formal rules exists, decision-makers appear to be under no obligation to abide by the written rules. Based upon the cases cited, the writer questions the notion of impersonal decisions predicated upon a system of formal rules. To the extent that there was a lack of clearly defined normative expectations, equity of treatment becomes more myth than reality.

We should not expect that the alternative model outlined above would apply in all cases since perhaps a majority of faculty have done nothing to merit particularistic treatment. For them, the system may appear to be meritocratic and impersonal. For most, it may be an equitable system. There are choices to be made and consequences to be anticipated. Some prefer the "...naivete of 'soulsearching' to the genuine vulgarity of 'soul-selling.' (Gouldner, 1970:499) People of courage and integrity need our support and encouragement but they also deserve to be warned about the anticipated consequences of their action. To perpetuate the myth of impersonal decision-making is to stand with the malevolent liars who know better. Should we choose suicide to avoid being murdered? (Gouldner 1962). It is risky to speak truth to power. What if academic culture is a product and instrument of class interest? (See Parenti 1978:216). Is impersonal decision-making a case of the "Emperor's Clothes"? This writer argues that the myth of impersonal decision-making is an instrument of Plutocratic Culture serving elite interests and a fraudulent ideology.

\section{REFERENCES}

Abrahamson, Mark. 1990. Sociological Theory: An Introduction to Concepts, Issues, and Research. Second edition. Englewood Cliffs, New Jersey:
Prentice Hall.

Berger, Peter L., and Thomas Luckmann. 1966. The Social Construction of Reality: A Treatise in the Sociology of Knowledge. Garden City, New Jersey: Prentice Hall.

Davis, Kingsley, and Wilbert E. Moore. 1945. "Some Principles of Stratification." The-Amexican Sociological Revie:y 10:2:242-240. .....

Gerth, H. H., and C. Wright Mills (editors and translators). 1946. From Max Weber: Essays in Sociology. New York: Oxford University Press.

Glaser, Barney G., and Anselm L. Strauss. 1967. The Discoven of Grounded Theory: Strategies for Qualitative Research. Chicago: Aldine Publishing Company.

Glaser, Barney G., and Anselm L. Strauss. 1964. "Awareness Contexts and Interaction." American Sociological Review 29, 669-679.

Gouldner, Alvin W. 1970. The Coming Crisis of Western Sociology. New York: Avon Books.

Gouldner, Alvin. 1962. "Anti-Minotaur: The Myth of a Value Free Sociology." Social Problems 9/3 (winter). 
Green, III, Charles S. 1986. Guidelines and Resources for Assessing Your Sociology Program. Washington, D. C.: American Sociological Association.

Hewitt, John P. 1991. Self and Society: A Symbolic Interactionist Social Psychology. Fifth edition. Boston: Allyn and Bacon.

Keller, Albert Galloway. 1963. Social Darwinism: Selected Essays of William Graham Sumner. Englewood Cliffs, New Jersey: Prentice Hall.

Graham Summer. Englewood Cliffs, New J People: The Collected Essays of
ills, C. Wright. 1962. Power, Politics, and Peoplantine C. Wright Mills, edited by Irving Louis Horowitz. New York: Ballantine Books.

Parenti, Michael. 1988. Democracy for the Few. Fifth edition. New York: St. Martin's Press.

Parenti, Michael. 1986. Inventing Reality: The Politics of the Mass Media. New York: St. Martin's Press.

New York: St. Martin's Press.
Parenti, Michael. 1978. Power and the Powerless. New York: St. Martin's

Press.
Parsons, Talcott (editor) (translated by A. M. Henderson and Talcott Parsons) 1947. Max Weber: The Theory of Social and Economic Organization. New York: Oxford University Press.

Per Facade of Due Process as a Substitute for Substantive Justice in Higher Education." Wisconsin Sociologist, 28-4:1721 .

Remender, Peter A. 1990. "A Critical View of the Publish or Perish Controversy." Wisconsin Sociologist, 27-2/3:39-45.

" 1986. "Community Service as Applied Sociology." Wisconsin Sociologist, 23-2/3:107-110.

Ryan, William. 1971. Blaming the Victim. New York: Vintage Books.

Rilliam Graham. 1883. What Social Classes Owe to Each Other. Caldwell, Idaho: The Caxton Printers, Ltd.

Sykes, Charles J. 1988. Profscam: Professors and the Demise of Higher Education. Washington, D. C.: Regnery Gateway.

Turner, Ralph. 1960. "Sponsored and Contest Mobility and the School System." American Sociologicall Revièw, 25:855-867.-
Metatheorizing in Sociology, by George Ritzer. (1991) Lexington, Mass.: Lexington Books. 362 pages.

George Ritzer argues that sociological theory is at a major crossroad. Sociology, as a discipline, is increasingly receptive to theoretical diversity (1990). What is absent to date, though, is an effort to explore and analyze this diversity. In other words, diversity can become self-perpetuating in the absence of some integrating force. As such, Ritzer's objective in Metatheorizing in Sociology (1991) is to present a grand theory of metatheory, or an overarching continum within which to place theoretical work. Ritzer values diversity, but also recognizes the importance of order and organization. His argument is that a conceptual map of sociological theory will synthesize diverse efforts, highlighting theoretical overlap and absences.

This objective is not without its critics. Turner (1991) and Skocpol (1986) view metatheory as too abstract and lacking real-world application. Collins (1986) argues that metatheory achieves no new creative end; it merely reevaluates existing theoretical work. In response to these and other (1990) criticisms, Ritzer emphasizes the heterogeneous nature of metatheory, when viewed from the purpose of the end product. By defining types of metatheory, Ritzer shows that only some metatheoretical work is abstract and a review of extant works increases understanding, and thus application to current issues, as well as providing theoretical cohesion. In this light, Ritzer even highlights the metatheoretical work of metatheory critics.

Ritzer states that there are three types of metatheory. First, metatheory can be conducted to increase the understanding of sociological theory. Factors pertinent to the comprehension of theory include the history and personality of the theorist, and the position of a particular theory relative to other theoretical work, both concurrent and historical. In other words, it is important to understand the theorist's goal, how their personal history influenced their work, and the extent to which their theory parallels or advances other theoretical knowledge. Further, a clear understanding of theory requires its placement within a larger societal context, both in terms of theory in other disciplines and the social world in general. Critics of this approach point out the dependence of the metatheorist on the work of others and the confining effect of theoryframing. Ritzer counters that all sociological research uses a building-block approach, and that categorization of theory provides opportunity for direction and comparison of future work.

Collins' (1989) analysis of Mead's theoretical work is an example of this type of metatheory. Collins reviews Mead's ideas, but also attempts to compare/contrast them with the work of others, such as Durkheim and Goffman. He also considers Mead's background, his family connections, his religious beliefs, and his intellectual connections. Within the macro context, Collins notes the influence of the political climate and changes occurring in the 